British Journal of Education, Society \&
Behavioural Science
$12(2): \begin{gathered}1-10,2016, \text { Article no.BJESBS.20634 } \\ \text { ISSN: 2278-0998 }\end{gathered}$
SCIENCEDOMAIN international
Www.sciencedomain.org

\title{
Grammar and Pragmatic Interrelations in the Construction of Popular Science Texts for Children
}

\author{
Patricia Vallejos ${ }^{1,2^{*}}$ \\ ${ }^{1}$ National University of the South, 12 de Octubre y San Juan, CP 8000 - Bahia Blanca, \\ Argentina. \\ ${ }^{2}$ National Scientific and Technical Research Council, Rivadavia 1917, C1033AAJ-CABA, \\ Argentina.
}

Author's contribution

The sole author designed, analyzed and interpreted and prepared the manuscript.

Article Information

DOI: 10.9734/BJESBS/2016/20634

Editor(s):

(1) Leonidas Kyriakides, Department of Education, University of Cyprus,

Cyprus.

(1) P. Moodley, University of Pretoria, South Africa.

(2) Jacob Gbemiga Arowolo, Federal College of Education, Kontagora, Nigeria. Complete Peer review History: http://sciencedomain.org/review-history/11746

Short Research Article

Received $1^{\text {st }}$ August 2015

Accepted $20^{\text {th }}$ September 2015

Published $8^{\text {th }}$ October 2015

\section{ABSTRACT}

Aims: To study in popular science books for children the stylistic selections that facilitate the passage from common sense to scientific knowledge. To provide a pragmatic explanation of the syntactic restrictions that characterises the scientific language of the texts.

Methodology: The work articulates the Hallydayan approach of Sydney School studies of science textbooks and the pragmatic perspective of Leech's "Principles of Textual Rhetoric".

Materials: Popular science books that cover physics and biology subjects'.

Results: The description and analysis of the stylistic options at the grammatical level supply a list of the syntactic restrictions constraint by the pragmatic features of this specific communicative context.

Conclusion: The analysis draws attention to the needs of the teachers that intervene in the learning process of scientific knowledge in order to develop the skills required for the purposes of school literacy of science. These include the mastering not only of field-specific terms but also of the grammar resources that structure scientific knowledge. On account of this, the work stresses the importance of the implementation, in science teachers' syllabus, of courses or tutorial sessions 
of scientific language in order to instruct future science educators in its linguistic skills and, in so doing, complement their professional literacy.

Keywords: Popular science for children; language of science; stylistic options; grammatical level; principles of textual rhetoric; grammar and pragmatic interrelations.

\section{INTRODUCTION ${ }^{1}$}

The study of scientific discourses within pedagogic contexts has been enriched in the last decades by Australian research programs in Systemic Functional Linguistics. These studies stress the value of scientific education in terms of language, text and discourse and concentrate on the features of scientific English in Elementary and High School Education (Halliday and Martin [1]; Martin and Veel [2]; Lemke, 1990 [3]; Christie and Martin et al. [4]). Along the same lines, the present work adopts Halliday's assumption that "Learning science is the same thing as learning the language of science" (2006: 70 [5]). On account of this, we agree with the distinguished linguist that, besides the specific subject-matter knowledge, educators need competences in the rhetoric features of scientific discourses. ${ }^{2}$ We consider this is an important aspect for teachers to develop the skills that students need to cope with the scientific language they learn in class or find in books (Butterworth and Thwaites, [6]).

Regarding the need for science teachers to be prepared to interpret the features of scientific English at lexicogrammar and semantic levels, this work stresses the importance of the implementation by curriculum ${ }^{5}$ developers, in

\footnotetext{
${ }^{1}$ A first version of this study was communicated at III Olomouc Linguistic Colloquium (Olinco), Jun. 6-8, 2013, Palaký University Art Centre, Olomouc, Czêch Republic.

2 In this respect, Myhill (2013 [7]) highlights the importance of teacher's grammatical competence, and points out the fact that limitations in teachers' grammatical content knowledge can generate student misconceptions.

${ }^{3}$ On this special topic Butterworth and Thwaites point out that "a great many of the thinking skills ... are forms of scientific thinking. (2011:139, underlined by the authors).

${ }^{4}$ We also contemplated in the work approaches that study the synergy between science and language and the way it benefits student's understanding of science content and language. Regarding this, Shanahan and Shea point out the "natural synergy between science and language" (2011:412 [8]), and its importance to develop children's understanding of academic words. In this sense, they sustain the students need to actively use words and explore in language-rich classrooms that focus not only on content but also on Incorporating English Language Teaching.

${ }^{5}$ In this paper, we adopt the concept of curriculum as "all planned learnings for which the school is responsible" (Marsh, 2009:5 [9]).
}

science teachers' syllabus, of courses or tutorial sessions in order to initiate future teachers in the knowledge of scientific English and how the language resources may be used strategically taking into account cognitive and psycho-social factors. ${ }^{6}$ Considering this, our work studies a sample of authentic materials taken from popular science books for children in order to show the ways in which not only technical terms but, principally, grammar structures work in the construction of texts to make the communication of scientific facts and concepts fit the linguistic and pragmatic competences of young learners.

The selection of these materials is based on the resemblance, in pragmatic and linguistic terms (i.e. the communicative purposes of genres and the linguistic options of style) between this type of informal pedagogic popularization and the teaching of science in the classroom oriented to young students (Lemke, 1990). ${ }^{7}$

In this sense, we agree with Shanahan and Shea on the importance of relaxed contexts for the efficiency of science teaching. They point out that "Students engaged in extended science discourse in a reduced-anxiety environment are provided with opportunities to construct knowledge" (2011: 411). This implies that the institution-formal contexts of schooling do not exclude the possibility of alternative means -as popular science books- for the sake of efficiency.

This approach is part of a current project on the analysis of multimodal resources for the construction of scientific knowledge in expert, pedagogic and popular science literature. ${ }^{8}$

\section{MATERIALS AND METHODS}

Among the important bibliography regarding different theories about the relation between grammar and pragmatics (Ariel, 2008 [10];

\footnotetext{
${ }^{6}$ See Hart (2003 [17]); Rothon (2006 [18]); Ben-Peretz ( 2011 [19])

Refer to Parkinson and Adendorff (2004 [20]).

8 See "Acknowledgements". In this context, my research incorporates a comparative study between popular science texts for children written in Spanish (published in Argentina) and English (UK and USA).
} 
Barton et al. [11]) Leech's seminal work Principles of Pragmatics [12] builds a rhetorical perspective of pragmatics articulating Halliday's [13] functional model of language with the speech acts theory $[14,15,16]$ principled pragmatics. In this work, the author enlarges Grice's perspective with other social principles of linguistic behaviour, the Principles of Politeness, Irony, and the Principle of Textual Rhetoric, a relevant set of maxims that focus on linguistic communication in terms of communicative goals and principles for an effective communication.

On account of this, in the present study, we opt for Leech's rhetorical model of pragmatics, in particular, for his Principles of Textual Rhetoric which provide us with conceptual and analytic instruments in order to explore the strategic use of grammar selections that facilitates the construction of effective texts and fulfill, at the same time, the purpose of communicating science subjects efficiently to children in primary schooling pedagogic context. From this perspective, our study centers on the description of the interplay between choices at grammatical level and pragmatic factors and analyses the way in which the principles and maxims of the PTR mediated by the constraints of communicative situations- determine grammar selections of style.

The analysis focuses on this set of principles:

$$
\begin{array}{ll}
\text { - } & \text { Processibility (sic) principle } \\
\text { - } & \text { Clarity principle } \\
\text { - Economy principle } \\
\text { - } & \text { Expressivity principle }
\end{array}
$$

According to the linguist, each of these principles recommends:

- Being humanly processible in ongoing time

- Being clear

- Being quick and easy

- Being expressive

The corpus collects a series of books for children aged four to twelve, designed for the popularization of physics and biology subjects ${ }^{9}$ in informal contexts. These informal communicative situations include these features:

- Producer of the text: A competent writer not necessarily a specialist- in a certain science

\footnotetext{
${ }^{9}$ See their complete references in the section corpus.
}

- Addressees: Young readers

- Purpose: To communicate scientific knowledge

- Rhetoric: Pedagogic - informal, not institutional

- Channel: Written language

\section{ANALYSIS OF GRAMMAR AND PRAGMATIC INTERRELATION IN POPULAR SCIENCE BOOKS FOR CHILDREN}

This section studies the way in which grammar and pragmatic interrelation works in the textual construction of scientific knowledge.

\subsection{The Processibility Principle}

In Leech's words, this principle recommends that the text must 'be humanly processible (sic) in ongoing time', i.e. texts should be produced in an easier way for the reader to decode them in time. The principle suggests the writer to take into account interrelated decisions about:

3.1.1 The ordering and prominence of certain elements in the syntactic structures of the clauses.

3.1.2 The degrees of linkage or subordination between different parts of the message.

\subsubsection{Maxim of "end-weight"}

Concerning this maxim, the order of the elements in the clause is an important grammatical device for the processing of scientific texts. This maxim is frequently motivated by "restrictions of human memory capacity in the left-to-right parsing of tree-structures." (Leech, 1986:66). According to it, in a syntactic structure, "light" constituents precede "heavy ones". In example 1, subjects are light constituents followed by heavy predicates:

1. The Universe is the name for space and everything in it, including stars, planets, and our own planet, the Earth. ...It is made of many billions of stars and planets, and enormous clouds of gas, separated by gigantic empty spaces (BOK). ${ }^{10}$

${ }^{10}$ The titles of the texts are identified by their initials: Bodies [B] [21]; The Horrible science of You [THS] [22]; First Encyclopedia of Science [FES [23]]; What's Science all about? [WSA] [24]; Space in 30 Seconds [S30's] [25]; Book of Knowledge [BOK] [26]; You and Your Body [Y\&Y] [27]; The Story of Astronomy and Space [SAS] [28]; The most Explosive Science Book in the Universe [ESB] [29]. 
This is not the case in 2:

2. Our planet, the Earth, and our nearest star, the Sun, are part of a Galaxy called the Milky Way (FES).

On the other hand, if an alternative syntactic pattern is required to facilitate the processing of a text in time, the Processibility Principle may contradict the maxim. ${ }^{11}$ This is the case of fronting topics.

Regarding the prominence of elements in the organization of a message, in expository texts the basic type in the popularization of scientific knowledge-, the message is codified in declarative sentences which follow the canonical order of English syntax. Therefore, the grammatical subjects -namely, scientific entities or phenomena- occupy the position of unmarked topics. The following text shows this basic structure:

3. A galaxy is an enormous group of stars. Galaxies are so big that it can take a ray of light thousands of years to travel across one. Earth is in the Milky Way galaxy. This galaxy is about 100,000 light years across [BOK].

However, this disposition of elements can be shifted, especially in structures where the Processibility Principle controls the syntax to give nuclear stress and make the fronted element -the topic- more noticeable. ${ }^{12}$ This grammatical strategy facilitates the processing of the texts in that, by stressing the topic of the message, it guides expectations in the reading process.

In some of these cases, contradictions appear when front positions are occupied by extended structures. This may be the case in example 4', where the author, by a fronting procedure, gives the problems preeminence to the science that 'has answers':

4. If you've ever wondered why there are different seasons in a year, or why things fall to the ground, the chances are physics has answers [WSA].

\footnotetext{
${ }^{11}$ Not always do Principles and Maxims operate coherently or have a correlative effect. Frequently, following one Principle or Maxim means infringing another. The contradictions may be between the Processibility Principle and its Maxim of EndWeight, the Economy Principle and the Processibility Principle or the Economy Principle and the Clarity Principle.

12 On this syntactic mechanism and its effects in scientific texts, see Thompson (2004 [30]).
}

Compare this text with the following rewording, in which the arrangement of the grammatical structures changes to an unmarked front position:

4'. Physics has answers to questions such as why there are different seasons in a year, or why things fall to the ground.

As a result of these procedures, left constituents of declarative sentences may change to heavy patterns, with the correlative infringement of the End-Weigh Maxim.

\subsubsection{Processibility and cohesion}

The second important issue to be considered is the degree of linkage or subordination between the different parts of the texts. This phenomenon of cohesion is a grammatical factor closely related to the Processibility Principle.

According to the "understanding-as-coherence" model of understanding texts, "a proposition has a greater likelihood of being recalled to the extent that it has more connections to other propositions in the text." (Graesser and Britton, 1996:345 [31]). This model confirms that, as inexplicit links between clauses or sentences may increase the processing or decoding time, explicit linkage is recommended to facilitate the processing of the information. ${ }^{13}$ In example 5, the connections result from pronominal reference and repetition:

5. The Universe contains billions of stars. They look small because they are very far away. In fact, each star is a giant ball of burning gas. Some stars have balls of rocks, called planets, orbiting (circling) around them [FES].

In 6 and 7, the connectors 'because' and 'so' explicit the logical relations of cause and consequence between the clauses:

6. Other reactions produce energy because they use less energy to break bonds and release more [ESB].

7. Warm molecules move fast and collide more, so raising the temperature speeds up reactions, and lowing the temperature slows them down [ESB].

\footnotetext{
${ }^{13}$ Halliday and Hasan in their most cited work, "Cohesion in English" (1976 [32]), study the multiple grammar devices that realize this phenomenon.
} 


\subsection{The Clarity Principle}

Leech associates two maxims to this principle, the Transparency Maxim, that states a direct and transparent relationship between message and text, and the Ambiguity Maxim, that recommends avoiding ambiguity.

\subsubsection{Transparency maxim}

Wignell, Martin and Eggins, [33] state that it is through definition and naming that a discipline establishes the inventory of what it can talk about, and the terms in which it can talk. In terms of the Clarity Principle, these are devices that transform the opacity of scientific texts, giving them some transparency. In the case of popular science, definitions "translate" the special language of sciences -its technical or specialized terminology- into common sense expressions:

8. A solid's elastic limit is the point beyond which it will break if it is stretched or bent further [ESB].

On the other hand, naming results from different structures. The predominant formulas in our corpus are [ $x$ is called /known as/ a]:

9. Falling meteoroids are called meteors. Some meteors actually hit the Earth's surface, these are called meteorites [BOK].

10. Together, the Sun and its planets are known as the Solar System [FES].

Or non-finite clauses [-ed participle called/ named $a$ ]:

11. In space, stars and planets form huge groups called galaxies. Our planet, the Earth, and our nearest star, the Sun, are part of a Galaxy called the Milky Way [FES].

\subsubsection{Ambiguity maxim}

There is a complementary relation between this and the transparency maxim: to avoid ambiguity contributes to transparency. In grammatical terms, to contribute to transparency, the writer must avoid syntactic ambiguity.

In this respect an important feature of scientific grammar to be considered is nominalization of verbs and adjectives. It is a regular and effective resource for the communication of science in specialized domains. But in some linguistic contexts this grammatical conversion causes syntactic ambiguity and the opacity of the text. In popular science for children, this is a problematic obstacle: young readers may not become aware that they are losing information, or that they lack the competence to recover the complete message. In Halliday's words, "Children learn first to talk in clauses; it is only later - and only when they can already read and write with facility- that they are able to replace these clauses with nominal groups" (2006: 173).

In example 12, children must be able to recognize in the noun-phrase 'The pull of its gravity' that 'gravity' is the subject of the nominalization of the verb 'to pull'. This may result a difficult task for them.

12. The sun is an average-sized star moving through space. The pull of its gravity keeps eight planets, their moons and other bodies travelling around it along elliptical (oval) paths called orbits [S30s'].

\subsection{The Economy Principle}

The principle 'Be quick and easy' suggests that, if one can shorten the text without damaging the message, this reduces the amount of time and effort involved in the process of decoding it. The Maxim of Reduction and the Maxim of Omission contribute to this effect.

\subsubsection{Maxim of reduction}

This maxim suggests reducing where possible. In science for children, this reduction is recommended when it simplifies the structures of the text.

Sometimes, the writer interrupts a clause at a point in order to comment on it, to add extra details, etc. These interpolations -signaled in writing by paired commas, dashes or parentheses- are separate messages.

13. Some stars have balls of rocks, called planets, orbiting (circling) around them [FES].

In 13 , the parentheses embrace the translation from the technical term orbiting to 'circling', its common sense equivalent. This interpolation is preceded by a naming structure between commas. Both cases may be considered as a contribution to reduce what otherwise would be a longer and complex structure. Compare 13 with its rewording in 13': 
13. Some stars have balls of rocks orbiting around; this means that they make circles around them. These stars are called 'planets'.

\subsubsection{Maxim of omission}

Some of the grammatical structures related with this maxim are adjacent clauses and non-finite clauses:

\subsubsection{Adjacent clauses}

These unlinked structures omit the logical relations between clauses -causal, consecutive, or a combination of both- so that the implicit connections must be inferred. Compare the unlinked clauses in 14 and 15 with their rewordings 14 ' and 15 ' that explicit their relations of cause or consequence:

14. Large parts of the planet's surface are covered with craters of various sizes. Astronomers believe that Mercury was bombarded by asteroids during the early stages of the Solar System's formation. [S30s']

15. Some people's skin is darker than others': it has more of a dye called melanin in it [Y\&Y].

14'. Large parts of the planet's surface are covered with craters of various sizes, that's why Astronomers believe that Mercury was bombarded by asteroids during the early stages of the Solar System's formation.

15'. Some people's skin is darker than others' because it has more of a dye called melanin in it.

\subsubsection{Non-finite clauses}

This kind of grammatical constructions may be realized by:

- ed clauses:

16. In space, stars and planets form huge groups called galaxies. Our planet, the Earth, and our nearest star, the Sun, are part of a Galaxy called the Milky Way. [FES]

\subsubsection{3 ing clauses}

17. <Mucus> It catches dust and bacteria, stopping them getting [sic] into your body [B].
18. Increasing pressure forces molecules together, which has the same effect as cooling [ESB]

\subsubsection{To-infinitive clauses:}

19. Sound and kinetic energy, need a substance, or medium, for their waves to travel through [WSA].

\subsubsection{Economy "at war" with clarity and processibility}

Not always do Principles and Maxims operate coherently, and following one Principle or Maxim frequently means infringing another. One of these conflicts is the contradiction between the Economy Principle and the Clarity and Processibility Principles.

The Economy Principle favours syntactic patterns in order to simplify the structures of texts. But, in spite of the economy and simplicity that result from grammatical strategies such as reducing the text by elision and reduction, these kinds of strategies may lead to unintelligibility, to 'obscure' the text, and, in this way, they confuse young readers, and infringe the Clarity Principle. In Leech's metaphorical terms, the Economy Principle is at war with the Clarity Principle. In this regard, he suggests that, in practice, a balance must be found between saving time and effort, and maintaining intelligibility, and that this balance may depend on contextual factors. In the case of the informal pedagogic contexts considered in this study, these factors may be collaborative tasks between teacher and student (1986:67).

\subsubsection{Omission of linkages}

In the case of adjacent clauses, the connections between the unlinked clauses are implicit and must be inferred by the reader. Consider this example:

20. Stars die ... when a massive star no longer has enough fuel to keep nuclear fusion occurring at its core (centre). The core collapses sharply under the force of gravity and incredible temperatures are generated [S30s'].

In 20, the missing of a consecutive linkage between both sentences restricts the automatic recognition of the causal function of the first. 
Example 21 also shows that, to make sense of the passage, the absence of a grammatical linkage between the last two sentences, forces an inference to restate the connections between them:

21. The respiratory system is made up of your lungs and the passages that lead to them. When you breath [sic] air into your lungs, oxygen from the air passes into your blood, which carries it around your body. The oxygen mixes with digested food to give you energy. Carbon dioxide is breathed out as waste [BOK].

The inference should direct young readers to interpret the function of the last sentence as a description of the final stage of breathing. In addition, the understanding of this sentence presupposes a reader who is aware that the 'waste' involved in the final stage of breathing not mentioned as such- is a secondary product of the process of mixing. In this sense, this operation might infringe the Clarity Principle, and, as a consequence, the processing of the text. At the same time, restating an omitted linkage might contradict the Processibility Principle in that it may also result in a more complex grammar and difficult the understanding of texts. As Wignell, Martin and Eggins explain, "unpacking a technical text (...) vastly increases text length and makes the amount of information to be processed relatively unmanageable" (1993: 164).

\subsubsection{Extended and interlocked definitions}

While extended texts infringe the Economy Principle, interlocked definitions are another factor that makes the text unintelligible and causes a conflict with the principles of Clarity and Processibility.

Although extended definitions provide a large amount of information, they may increase the text's length, and thus, turn the processing of the information relatively unmanageable. In this regard, extended definitions include not only a reformulation of the concept or reference of an object or phenomenon, but also a description of its characteristics, parts, forms or functions, and other details (Zimmerman, 1989 [34]). This kind of definitions may lead to grammar complexity, and, as a result, to a conflict between the Clarity and Processibility principles. In this respect, compare the definitions of "Our Solar System" in the passages from FES (22), BOK (23) and the extended definition in WSA (24):
22. The Sun is a star. It has eight planets, including Earth, orbiting around it. Together, the Sun and its planets are known as the Solar System [FES].

23. The word solar means "of the Sun". Our Solar System lies about 28,000 light years away from the middle of the Milky Way. As well as the Sun and the nine planets that orbit it, it is made up of moons, chunks of rock and huge amounts of dust, metal and icy debris [BOK].

24. Planets are huge balls of matter that orbit a star. Some are made of solid rock; others are mostly made of gas. The Earth is just one of eight planets which orbit the Sun. Together, the Sun and the planets make up our Solar System. Our Sun isn't the only star with planets orbiting it -many other stars have them, too.

Each planet's orbit is a different size, which means it takes some of them longer to go around the Sun than others. One year is the amount of time it takes a planet to orbit the Sun once. So how long a year is depends on which planet you're on [WSA].

Text 24 exemplifies the problems implicated in the processing and understanding of what Halliday calls 'interlocked definitions'. In this respect, the grammarian points out that "a technical construction of this kind, in which the terms interlock and are used to define each other, does present the learner with a considerable intellectual task. Writers sometimes try to make the task simpler by adding further definitions, not realizing that in a construct of this kind the greater the number of things defined, the harder it becomes to understand" (2006:16).

\subsection{The Expressivity Principle}

The Expressivity Principle is connected with effectiveness in that it refers to the expressive and aesthetics aspects of communication. ${ }^{14}$ These aspects have to do with effective communication because they play an important role in fulfilling communicative purposes -in functional terms, those which define the discursive genre. Both aspects relate essentially to the principal purpose of scientific popularization texts, i.e. to make scientific subjects more attractive in order to captivate

\footnotetext{
${ }^{14}$ Leech considers that, compared with the other principles, the Expressivity Principle is "more diffuse and difficult to define" (Leech,1986:68). It associates with the expressive and aesthetic aspects of the texts.
} 
children's interests, which is a very relevant point for the study of scientific popularization meant for children. Considering the specific aims of this study, focused on the grammar selections of style, we center the analysis on the grammar resources that realize the expressivity of the texts. ${ }^{15}$

Different grammatical devices realize the expressivity of texts. In these books, the most salient of these are interrogative and exclamative sentences and comparative structures.

\subsubsection{Interrogative sentences}

These structures have a central pragmatic function in order to activate the curiosity and interest of young readers. They appear in titles:

\section{5. "What's Science all about?" [WSA]}

Or in the opening of different sections:

26. What's life? What's the Universe made of?; Do things in Space work in the same way that things on Earth? [WSA]

27. What can you see in the night sky? What keeps the Universe together?; How does Hubble work? [SAS]

\subsubsection{Exclamative sentences}

In these sentences, expressivity functions to surprise, to provoke admiration or to stir some kind of awareness. These pragmatic effects may change the attitudes of indifference towards scientific or technical achievements.

28. Danger, Humans! Although Earth is an ideal home for humans, the way we're treating our planet is making it less hospitable [SAS]

29. The Universe is everything that exists. It's phenomenally huge. Imagine something as big as you can, multiply it by a billion and you're still nowhere near how big it is! [S30's]

30. Bet you never knew! In 2000, four London-based scientists invented a new shoebox that used laughing gas to kill the bacteria that make [sic] cheesy smells in your footwear. I bet the bacteria died happy [THS]

\footnotetext{
${ }^{15}$ On aesthetic aspects in popular science books for children written in Spanish, see Vallejos and Palmucci, 2011 [35].
}

\subsubsection{Comparative structures}

These structures are a frequent resource to describe or explain scientific information. They approach sciences to young readers by reference to their everyday experience.

31. There's little let-up either because its atmosphere acts like a really thick blanket, keeping in all that heat [S30s']

32. White blood cells are like soldiers in an army, defending our bodies against tiny invaders called germs [B]

33. Our eyelids help to keep our eyes clean. They act a bit like car windscreen wipers when we blink [B]

\section{CONCLUSION}

This approach is a 'how' and 'why' investigation on the construction of scientific knowledge in popular science books for children. In this context, 'how' signifies 'by what means', i.e. what kind of linguistic resources are selected to construct the scientific meanings in these materials, and 'why' refers to a pragmatic interpretation of the forces that provoke these particular options.

With respect to the 'how' question, the study focuses on grammatical resources of style to analyse the strategic selections of syntactic structures and transformations that work to provide alternative structures in order to solve grammar intricacy.

Regarding the 'why' question, it refers to the analyses of the origin of the pragmatic forces that restrict the grammatical selections: cognitive factors associated with the comprehension of texts; psychosocial, concerned with the individual and social conditions of the learners age, range of maturity, interests; and curriculum, concerning the "permanent subjects that embody essential knowledge" (Marsh, 2009:24).

To conclude, we present the principal aspects of this research that may be considered a contribution to future science teacher's education:

- It exposes, in terms of Leech's Principles of Textual Rhetoric, the role of the grammatical options of style in science popularization books for children in order to understand the way in which syntactic structures make the communication of 
science facts and concepts fit the linguistic and pragmatic competences of young learners.

- It explains these rhetorical options of style as linguistic strategies for a successful communication of scientific knowledge in informal and relaxed contexts.

- It provides the basic resources to prepare science teachers to interpret the stylistic preferences that characterize popular scientific English in grammatical and pragmatic terms.

- It supports the value of a pedagogy which centers on how scientific language and texts work.

As a general conclusion we draw attention to the needs of the teachers that intervene in the learning process of scientific knowledge in order to develop the skills required for the purposes of school literacy of science. These include mastering not only field-specific terms but also the grammar resources that structure scientific knowledge, many of which have been considered in the analysis: logical relationships (of cause, consequence and effect), comparisons, definitions, explanations, nominalizations. On account of this, the present work stresses the importance of the implementation of classes or tutorial sessions of scientific language in the science teachers' syllabus, in order to instruct future science educators in these linguistic skills and, in so doing, complement their professional literacy.

\section{ACKNOWLEDGEMENTS}

This paper is a contribution to the research project "The textual construction of scientific knowledge", funded by the National University of the South (Bahía Blanca, Argentine Republic).

\section{COMPETING INTERESTS}

Author has declared that no competing interests exist.

\section{REFERENCES}

1. Halliday $M$, Martin J. Writing Science. London: Falmer Press; 1993.

2. Martin J, Veel R, editors. Reading science. London: Routledge; 1998.

3. Lemke J. Talking science: language, learning and values. Norwood, NJ: Ablex Publishing; 1990.
4. Christie F, Martin J, editors. Genre and Institutions. London: Continuum; 2000.

5. Halliday M. Some grammatical problems in Scientific English. In: Webster J. editor. The Language of Science. London: Continuum; 2006.

6. Butterworth J, Thwaites G. Thinking skills. Cambridge University Press; 2005>2011.

7. Myhill D, Jones, Watson A. Grammar matters: How teachers grammatical knowledge impacts on the teaching of writing. Teaching and Teacher Education. 2013;36:77-91.

8. Shanahan T, Shea L. Incorporating english language teaching through science for $k-2$ teachers. J Sci Teacher Educ. The Association for Science Teacher Education. 2012;23:407-428.

9. Marsh C. Key Concepts for Understanding Curriculum. $4^{\text {th }}$ edition. London and New York: Taylor \& Francis Routledge; 2009.

10. Ariel $M$. Pragmatics and grammar. Cambridge University Press; 2008.

11. Barton E. Nonsentential constituents. A theory of grammatical structure and pragmatic interpretations. AmsterdamPhiladelphia: John Benjamins; 1990.

12. Leech G. Principles of Pragmatics. London and New York: Longman; 1983> Ed. 1986.

13. Halliday M. Explorations in the functions of language; 1973.

14. Austin J. How to do things with words. Cambridge; 1962.

15. Searle J. Speech acts: An essay in the philosophy of language. Cambridge; 1969.

16. Grice JP. Logic and conversation. In: Cole $P$, Morgan J, editors. Syntax and Semantics; 1975.

17. Hart J, Lee O. Teacher professional development to improve science and literacy achievement of english language learners. Bilingual Research Journal. 2003;27:475-501.

18. Rhoton J, Shane P. Scientific literacy: The main goal of science education; 2006.

Available:http://www2.phy.ilstu.edu/ wenni ng/thsp/chapters/Scientific Literacy[1].pdf

19. Ben-Peretz M. Teacher knowledge: What is it? How do we uncover it? What are its implications for schooling? Teaching and Teacher Education. 2011;27:3-9.

20. Parkinson J, Adendorff R. The use of popular science articles in teaching scientific literacy. English for Specific Purposes. 2004;23(4):379-396.

21. Ardagh P. Bodies. London: Scholastic Children's Books; 2009. [B]. 
22. Arnold N. The horrible science of you. London: Scholastic Children's Books; 2009. [THS].

23. Firth R. First encyclopedia of science. London: Usborne Publishing Ltd; 2010. [FES].

24. Frith A, Maskell H, Gillespie L, Davies K. What's Science all about? London: Usborne Publishing Ltd; 2010. [WSA].

25. Gifford C. Space in 30 Seconds. London: Ivy Press; 2013. [S30's].

26. Helbrough E, editor. Book of knowledge. London: Usborne Publishing Ltd; 2003. [BOK].

27. Meredith S, Needham K, Unwin M. You and Your Body. London: Usborne publishing Itd; 2003. [Y\&Y].

28. Stowell L, Allen P. The story of astronomy and space. London: Usborne publishing Itd; 2009. [SAS]

29. Watts C. The most explosive science book in the universe. London: Dorling kindersley Itd; 2012. [ESB].
30. Thompson G. Introducing Functional Grammar. London: Arnold; 2004.

31. Graesser A, Britton B. Five metaphors for Text Understanding. In: Models of Understanding Text, edited by Britton B, Graesser A. New Jersey: Lawrence Erlbaum Associates. 1996;341-351.

32. Halliday M, Hasan R. Cohesion in English. New York: Longman; 1976.

33. Wignell $\mathrm{P}$, Martin J, Eggins $\mathrm{S}$. The discourse of geography: Ordering and explaining the experiential world. In Halliday M, Martin J. Op. Cit. 1993; 136-165.

34. Zimmerman F. English for science. New York: Pearson; 1989.

35. Vallejos P, Palmucci D. Recursos de la divulgación científica en la literatura para niños. Construcción verbal y visual del disparate". En Anclajes. Impreso: Español. 2011;15(2):165-188.

Available:http://www.fchst.unlpam.edu.ar/oj s/index.php/anclajes (pp.79-102) Español.

(c) 2016 Vallejos; This is an Open Access article distributed under the terms of the Creative Commons Attribution License (http://creativecommons.org/licenses/by/4.0), which permits unrestricted use, distribution, and reproduction in any medium, provided the original work is properly cited.

Peer-review history:

The peer review history for this paper can be accessed here: http://sciencedomain.org/review-history/11746 